This item was submitted to Loughborough's Research Repository by the author.

Items in Figshare are protected by copyright, with all rights reserved, unless otherwise indicated.

\title{
Determination of mode I and II adhesion toughness of monolayer thin films by circular blister tests
}

PLEASE CITE THE PUBLISHED VERSION

https://doi.org/10.1016/j.tafmec.2018.01.006

\section{PUBLISHER}

(C) Elsevier

\section{VERSION}

AM (Accepted Manuscript)

\section{PUBLISHER STATEMENT}

This work is made available according to the conditions of the Creative Commons Attribution-NonCommercialNoDerivatives 4.0 International (CC BY-NC-ND 4.0) licence. Full details of this licence are available at: https://creativecommons.org/licenses/by-nc-nd/4.0/

\section{LICENCE}

CC BY-NC-ND 4.0

\section{REPOSITORY RECORD}

Harvey, Christopher, Simon Wang, Bo Yuan, Rachel Thomson, and Gary Critchlow. 2018. "Determination of Mode I and II Adhesion Toughness of Monolayer Thin Films by Circular Blister Tests". figshare. https://hdl.handle.net/2134/28040. 


\title{
Determination of mode I and II adhesion toughness of monolayer thin films by circular blister tests
}

\author{
Christopher M. Harvey ${ }^{\mathrm{a}}$, Simon Wang ${ }^{\mathrm{a}, \mathrm{b}, *}$, Bo Yuan ${ }^{\mathrm{a}}$, \\ Rachel C. Thomson ${ }^{\mathrm{c}}$ and Gary W. Critchlow ${ }^{\mathrm{c}}$ \\ ${ }^{a}$ Department of Aeronautical and Automotive Engineering, Loughborough University, \\ Loughborough, Leicestershire LE11 3TU, UK \\ ${ }^{b}$ College of Mechanical and Equipment Engineering, Hebei University of Engineering, \\ Handan 056038, China \\ ${ }^{c}$ Department of Materials Engineering, Loughborough University, \\ Loughborough, Leicestershire LE11 3TU, UK
}

\begin{abstract}
Mechanical models are developed to determine the mode I and II adhesion toughness of monolayer thin films using circular blister tests under either pressure load or point load. The interface fracture of monolayer thin film blisters is mode I dominant for linear bending with small deflection while it is mode II dominant for membrane stretching with large deflection. By taking the advantage of the large mode mixity difference between these two limiting cases, the mode I and II adhesion toughness are determined in conjunction with a linear failure criterion. Thin films under membrane stretching have larger adhesion toughness than thicker films under bending. Experimental results demonstrate the validity of the method.

Keywords: adhesion toughness, circular blisters, energy release rate, interface fracture, thin films
\end{abstract}

\footnotetext{
* Corresponding Author
}

Email addresses: c . m . harvey@lboro . ac .uk (C. M. Harvey); s . wang@lboro . ac . uk (S. Wang*),

b.yuan@lboro.ac.uk (B. Yuan); r.c.thomson@lboro.ac.uk (R. C. Thomson); 


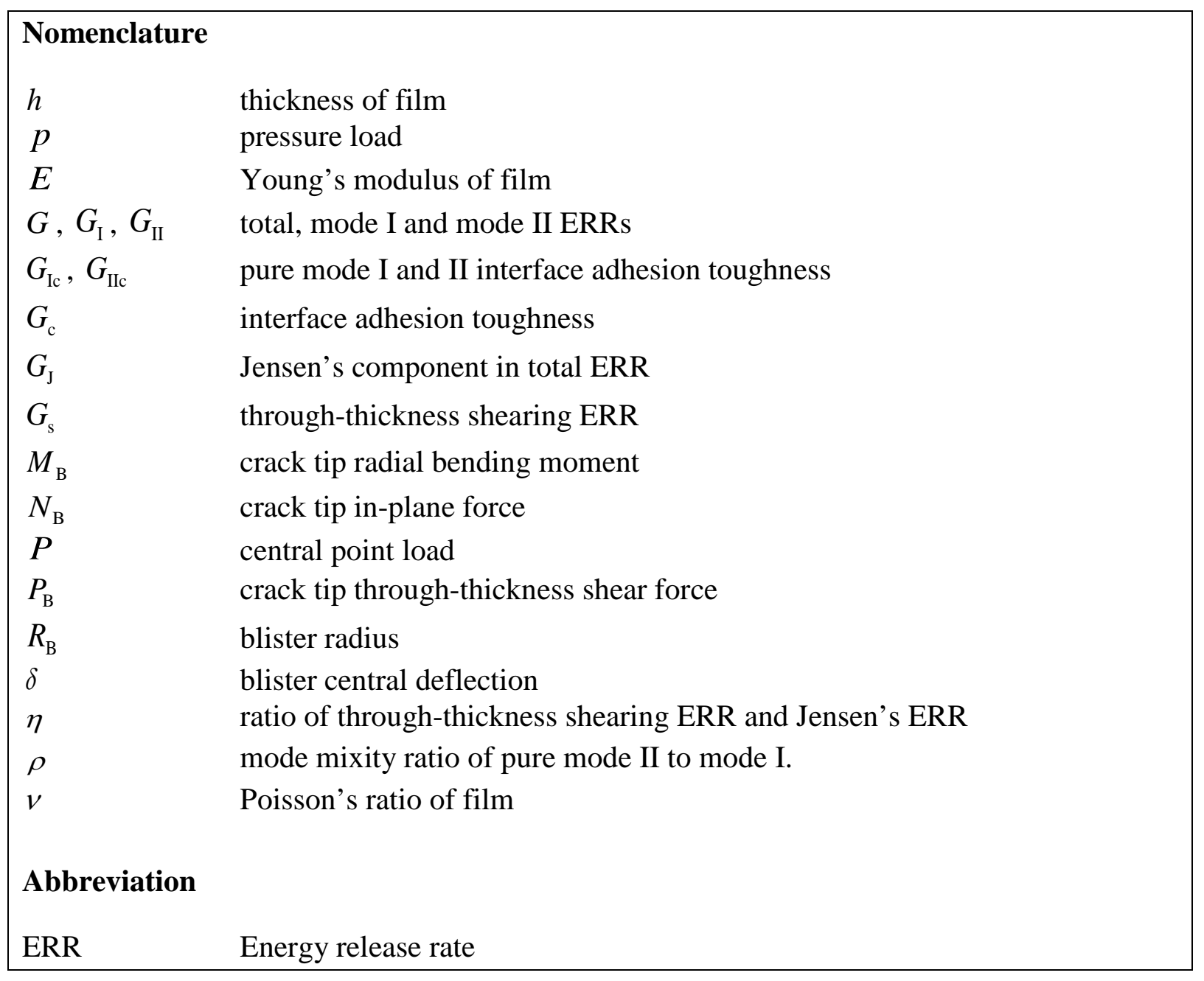

\section{Introduction}

Thin solid films are found in many different applications fulfilling various roles $[1,2]$ such as confinement of electric charge in integrated electronic circuits, in thermal insulation like in thermal barrier coatings (TBCs), and in surface coatings that protect against corrosion, friction and wear. Although thin films are not usually expected to have a primary loadcarrying capability, their adhesion toughness is still a major concern in engineering applications due to various factors such as buckling [3-9] or pockets of energy concentration [10-15], which can cause delamination and then often, loss of function.

Several tests to determine the adhesion toughness of a film to its substrate have been developed over the past century, for example, peeling tests [16,17], indentation tests [18], scratching tests [19], and blister tests [20-22]. Blister tests are widely applied in the fields of microelectronics and coatings. The first blister test was reported by Dannenberg in 1961 [20], which was further developed by Jensen [21,22]. In addition, multiple theoretical models have 
been developed [23-25] to correlate the adhesion toughness of thin films with the blister morphology that is induced by either a pressure load or a point load. Films, such as graphene, and substrates with various material properties and thickness are employed in the blister tests; therefore, mechanical models are needed for the limits of membrane stretching with large deflections, linear bending with small deflections, and the transition between these limits, in order to derive a film's adhesion toughness. Furthermore, adhesion toughness is influenced by through-thickness shearing and film sliding [26] and its effect on mode mixity. This gives the idea of the present work: By taking advantage of the large difference in mode mixity between cases of linear bending with small deflections, and membrane stretching with large deflections, the mode I and II adhesion toughnesses can be determined.

The present work aims to develop mechanical models to determine the mode I and II adhesion toughness of thin films by using circular blister tests. A mechanical model for circular blisters under a pressure load is developed in Section 2 while a mechanical model for circular blisters under a point load is developed in Section 3. The developed models are assessed with experimental results [27] in Section 4. Conclusions are drawn in Section 5.

\section{Analytical mechanical model for the circular blister test with a pressure load}

In this section, a mechanical model is developed to determine the mode I and II adhesion toughness between thin films and thick substrates by using the circular blister test with a pressure load. Figure 1 shows a circular blister under pressure $p$. The blister radius is $R_{\mathrm{B}}$ with the subscript B denoting the blister tip, and the central deflection is represented by $\delta$. The thickness of the film $h$ is much smaller than the thickness of the substrate, and the substrate is therefore assumed to have negligible global deformation due to the film deformation. Both the film and substrate materials are assumed to be homogeneous and isotropic. The film material has Young's modulus $E$ and Poisson's ratio $v$. The development here includes both linear bending for small deflection and membrane stretching for large deflection. These two cases are often used in experimental tests [27-29] to determine adhesion toughness of thin films. 


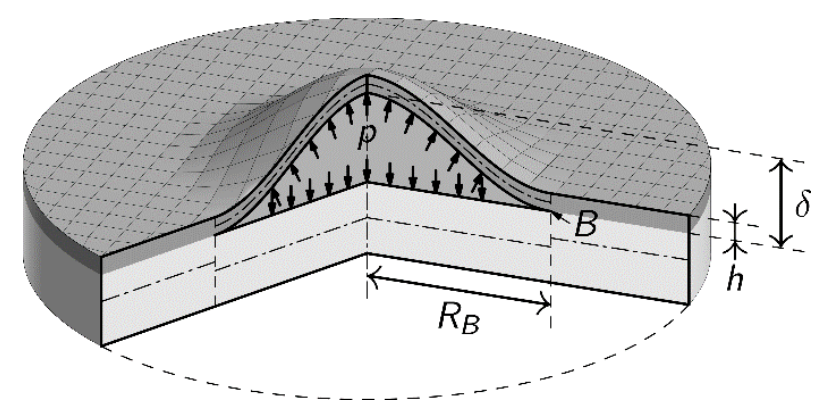

Fig. 1. A circular blister test with a thin film under a pressure load on a thick substrate.

Based on 2D elasticity partition theories [26,30-32], the mode I and II energy release rates (ERRs) can be written in the following forms:

$$
\begin{gathered}
G_{\mathrm{I}}=0.6227 \times \frac{6}{E h^{3}}\left(1-v^{2}\right)\left(M_{\mathrm{B}}-\frac{N_{\mathrm{B}} h}{4.450}+\frac{P_{\mathrm{B}} h}{1.0063}\right)^{2} \\
G_{\mathrm{II}}=0.3773 \times \frac{6}{E h^{3}}\left(1-v^{2}\right)\left(M_{\mathrm{B}}+\frac{N_{\mathrm{B}} h}{2.697}\right)^{2}
\end{gathered}
$$

The loads at the crack tip in the thin film are the bending moment $M_{\mathrm{B}}(\mathrm{Nm} / \mathrm{m})$, the in-plane force $N_{\mathrm{B}}(\mathrm{N} / \mathrm{m})$, and the through-thickness shear force $P_{\mathrm{B}}(\mathrm{N} / \mathrm{m})$. They take different values in linear bending for small deflection and membrane stretching for large deflection; hence, the mode mixity, $G_{\mathrm{II}} / G_{\mathrm{I}}$ or $\rho$, also takes different values.

\subsection{Linear bending mechanical model for small deflection}

For small deflections within the linear range, the crack tip loads in Eqs. (1) and (2) are [57]

$$
M_{\mathrm{Bb}}=\frac{1}{8} p R_{\mathrm{B}}^{2}, N_{\mathrm{Bb}}=0 \text { and } P_{\mathrm{Bb}}=\frac{1}{2} p R_{\mathrm{B}}
$$

The subscript b denotes bending with small deflections. The deflection $\delta_{\mathrm{b}}$ at the centre of the blister is

$$
\delta_{\mathrm{b}}=\frac{3}{16} \frac{\left(1-v^{2}\right) p R_{\mathrm{B}}^{4}}{E h^{3}}
$$

Substituting Eqs. (3) and (4) into Eqs. (1) and (2) gives

$$
G_{\mathrm{I}}=0.6227 \times \frac{1}{2} p \delta_{\mathrm{b}}(1+\lambda)^{2}
$$




$$
G_{\mathrm{II}}=0.3773 \times \frac{1}{2} p \delta_{\mathrm{b}}
$$

where

$$
\lambda=\frac{P_{\mathrm{Bb}} h}{1.0063 M_{\mathrm{Bb}}}=\frac{4 h}{1.0063 R_{\mathrm{B}}}
$$

which represents the through-thickness shear effect. By combining Eqs. (5) and (6), the total ERR can be expressed as

$$
G=G_{\mathrm{S}}+G_{\mathrm{J}}=G_{\mathrm{J}}(1+\eta)
$$

in which

$$
\begin{gathered}
G_{\mathrm{J}}=\frac{1}{2} p \delta_{\mathrm{b}} \\
\eta=\frac{G_{\mathrm{S}}}{G_{\mathrm{J}}}=0.6227 \lambda(2+\lambda)
\end{gathered}
$$

The ERR component $G_{\mathrm{J}}$ is from Jensen's work [5-7], which does not account for throughthickness shear. The additional ERR contribution from the crack tip through-thickness shear force $P_{\mathrm{Bb}}$ is the ERR component $G_{\mathrm{S}}$, which is related to $G_{\mathrm{J}}$ through the ratio $\eta$.

The mode mixity $\rho=G_{\text {II }} / G_{\text {I }}$ is readily obtained as

$$
\rho=\frac{G_{\mathrm{II}}}{G_{\mathrm{I}}}=0.6059 \frac{1}{(1+\lambda)^{2}}
$$

It is seen that the effect of through-thickness shear is to decrease the mode mixity and consequently to reduce the adhesion toughness. Figure 2a shows the variation of mode mixity $\rho$ with respect to $R_{\mathrm{B}} / h$, which, as per Eq. (7), is effectively $\lambda$. The mode mixity approaches zero (pure mode I) for small $R_{\mathrm{B}} / h$ (or large $\lambda$ ), and it decreases with increasing film thickness and approaches 0.6059 for large $R_{\mathrm{B}} / h$ (or small $\lambda$ ). 
(a)

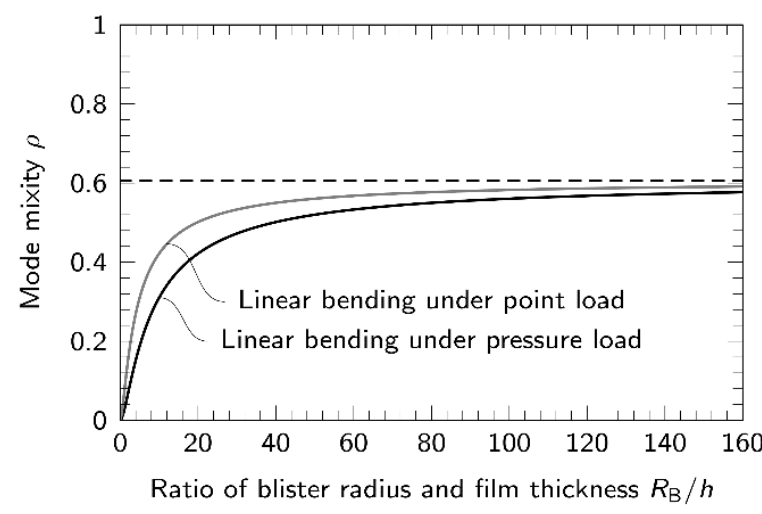

(b)

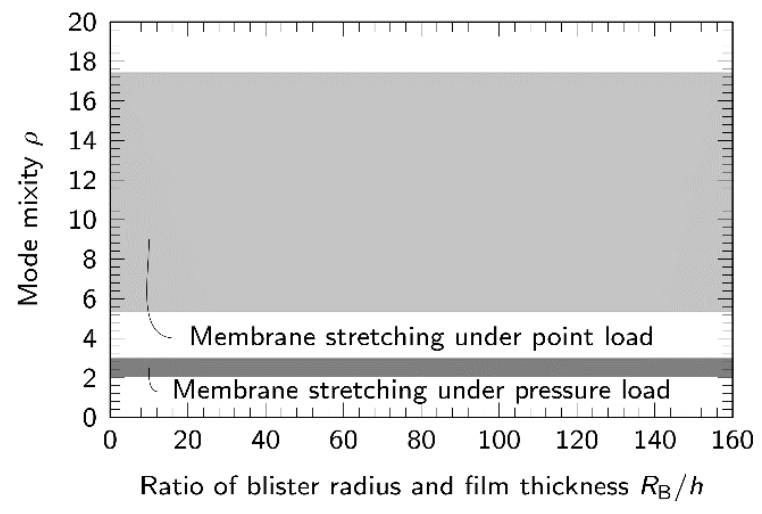

Fig. 2. Variation of mode mixity $\rho$ with respect to $R_{\mathrm{B}} / h$ for linear bending under point or pressure loads (a), and for membrane stretching under point or pressure loads (b).

The linear failure criterion, shown in Eq. (12), can be used to derive the mode I and II adhesion toughness $G_{\text {Ic }}$ and $G_{\text {IIc }}$. The linear failure criterion is an accurate failure criterion for interfaces with low adhesion toughness [10-13,26,33,34].

$$
\frac{G_{\text {I }}}{G_{\text {Ic }}}+\frac{G_{\text {II }}}{G_{\text {IIc }}}=1
$$

For any given mode mixity $\rho$, the corresponding adhesion toughness $G_{\mathrm{c}}$ can be obtained as the following by combining Eq. (12) with $G_{\mathrm{c}}=G=G_{\mathrm{I}}+G_{\mathrm{II}}$ :

$$
G_{\mathrm{c}}=\frac{(1+\rho) G_{\text {Ic }} G_{\text {II }}}{\rho G_{\text {Ic }}+G_{\text {II }}}
$$

By choosing two values of $R_{\mathrm{B}} / h$ with the corresponding mode mixities $\rho_{1}$ and $\rho_{2}$, and the measured adhesion toughness $G_{\mathrm{c} 1}$ and $G_{\mathrm{c} 2}$, the mode I and II adhesion toughness $G_{\text {Ic }}$ and $G_{\text {IIc }}$ can be determined from Eq. (13) as

$$
\begin{gathered}
G_{\mathrm{Ic}}=\frac{G_{\mathrm{c} 1} G_{\mathrm{c} 2}\left(\rho_{1}-\rho_{2}\right)}{\rho_{1} G_{\mathrm{c} 1}\left(1+\rho_{2}\right)-\rho_{2} G_{\mathrm{c} 2}\left(1+\rho_{1}\right)} \\
G_{\mathrm{IIc}}=\frac{G_{\mathrm{c} 1} G_{\mathrm{c} 2}\left(\rho_{1}-\rho_{2}\right)}{G_{\mathrm{c} 2}\left(1+\rho_{1}\right)-G_{\mathrm{c} 1}\left(1+\rho_{2}\right)}
\end{gathered}
$$

To obtain accurate predictions of $G_{\text {Ic }}$ and $G_{\text {IIc }}$ from Eqs. (14) and (15), it is better to use a large mode mixity difference $\left(\rho_{1}-\rho_{2}\right)$. This can be achieved by choosing a small value of $R_{\mathrm{B}} / h$ for $\rho_{1}$, and a large value of $R_{\mathrm{B}} / h$ for $\rho_{2}$. The fracture resistance curve can be 
obtained based on Eqs. (4), and (7) to (10). It is found that $G_{\mathrm{c} 1}$ can be expressed by a higherorder polynomial function in terms of $R_{\mathrm{B}} / h$, hence the adhesion toughness maybe unreliable for small experimental values of $R_{\mathrm{B}} / h$. To overcome this difficulty, an alternative method is developed next.

\subsection{Membrane stretching mechanical model for large deflection}

At the limit of membrane stretching, the crack tip loads in Eqs. (1) and (2) for the circular blister of radius $R_{\mathrm{B}}$ under pressure load $p$ become [5-7]

$$
\begin{gathered}
M_{\mathrm{Bm}}=\frac{h}{4} \frac{\left(E h p^{2} R_{\mathrm{B}}^{2}\right)^{1 / 3}}{\left[3\left(1-v^{2}\right) \varphi(v)\right]^{1 / 2}} \\
N_{\mathrm{Bm}}=\left(E h p^{2} R_{\mathrm{B}}^{2}\right)^{1 / 3} \varphi(v) \\
P_{\mathrm{Bm}}=\frac{1}{2} p R_{\mathrm{B}}
\end{gathered}
$$

The subscript $m$ denotes the membrane limit case and the parameter $\varphi(v)$ is

$$
\varphi(v)=\frac{(1.078+0.636 v)^{2 / 3}}{2\left[6\left(1-v^{2}\right)\right]^{1 / 3}}
$$

The deflection $\delta_{\mathrm{m}}$ at the centre of the blister is

$$
\delta_{\mathrm{m}}=f(v)\left(\frac{p R_{\mathrm{B}}^{4}}{E h}\right)^{1 / 3}
$$

with

$$
f(v)=0.9635\left[\frac{3(1-v)}{7-v}\right]^{1 / 3}
$$

The mode I and II energy release rates (ERRs) can then be obtained [26,30-32] as follows:

$$
\begin{gathered}
G_{\mathrm{I}}=0.6227 \times \frac{p \delta_{\mathrm{m}}}{8} \frac{(0.7578-0.1429 v)^{2}}{\varphi(v) f(v)} \\
G_{\mathrm{II}}=0.3773 \times \frac{p \delta_{\mathrm{m}}}{8} \frac{(1.400+0.2358 v)^{2}}{\varphi(v) f(v)}
\end{gathered}
$$


The effect of the through-thickness shear force $P_{\mathrm{B}}$ in Eq. (1) disappears at the membrane stretching limit. Note, however, that in the case of multilayer membranes, interlayer sliding can activate the effect again and this results in extra mode I ERR contribution. This has been considered in detail in a study on the adhesion toughness of multilayer graphene membranes using circular blister tests [26]. Excellent agreement on adhesion toughness was observed in that study [26] between predictions from the mechanical model and experimental results. In the present work, only monolayer membranes are considered. From Eqs. (20), (22) and (23), the total ERR is

$$
G=\zeta(v) \frac{p \delta_{\mathrm{m}}}{f(v)}
$$

in which the parameter $\zeta$ is

$$
\zeta(v)=\frac{1}{8 \varphi(v)}+\frac{\left(1-v^{2}\right) \varphi(v)^{2}}{2}
$$

The mode mixity $\rho=G_{\text {II }} / G_{\text {I }}$ is obtained from Eqs. (22) and (23) as

$$
\rho=0.6059\left(\frac{1.400+0.2358 v}{0.7578-0.1429 v}\right)^{2}
$$

It varies from 2.0680 for $v=0$ to 2.9634 for $v=0.5$, and remains constant during radial growth. It is shown in Fig. $2 \mathrm{~b}$ as the dark shaded area. The adhesion toughness $G_{\mathrm{c}}$ therefore remains constant with mode II dominant, and consequently it is expected to be larger than the adhesion toughness of films under linear bending.

Equations (14) and (15) cannot be applied here to determine $G_{\text {Ic }}$ and $G_{\text {IIc }}$ when using the membrane mechanical model alone; however, when used in conjunction with the linear bending model, more accurate predictions for $G_{\text {Ic }}$ and $G_{\text {IIc }}$ can be determined than from using just the linear bending model alone. Eqs. (14) and (15) now change to be

$$
\begin{gathered}
G_{\mathrm{Ic}}=\frac{G_{\mathrm{cb}} G_{\mathrm{cm}}\left(\rho_{\mathrm{b}}-\rho_{\mathrm{m}}\right)}{\rho_{\mathrm{b}} G_{\mathrm{cb}}\left(1+\rho_{\mathrm{m}}\right)-\rho_{\mathrm{m}} G_{\mathrm{cm}}\left(1+\rho_{\mathrm{b}}\right)} \\
G_{\text {IIc }}=\frac{G_{\mathrm{cb}} G_{\mathrm{cm}}\left(\rho_{\mathrm{b}}-\rho_{\mathrm{m}}\right)}{G_{\mathrm{cm}}\left(1+\rho_{\mathrm{b}}\right)-G_{\mathrm{cb}}\left(1+\rho_{\mathrm{m}}\right)}
\end{gathered}
$$

The improved accuracy comes from the fact that the linear bending model is mode I dominant while the membrane stretching model is mode II dominant. 


\section{Analytical mechanical model for the circular blister test with a point load}

\subsection{Linear bending mechanical model for small deflection}

Figure 3 shows a circular blister of radius $R_{\mathrm{B}}$ under a central point load $P$.

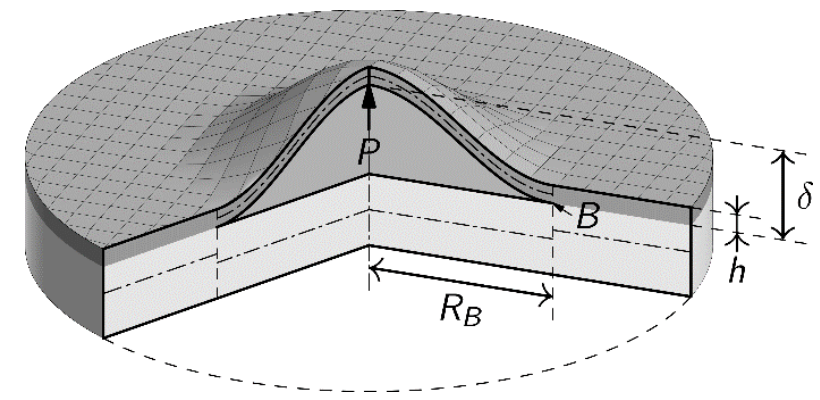

Fig. 3. A circular blister test with a thin film under a central point load on a thick substrate.

For small deflections within the linear range, the crack tip loads in Eq. (1) are [5-7]

$$
M_{\mathrm{Bb}}=\frac{P}{4 \pi}, N_{\mathrm{Bb}}=0 \text { and } P_{\mathrm{Bb}}=\frac{P}{2 \pi R_{\mathrm{B}}}
$$

The deflection $\delta_{\mathrm{b}}$ at the centre of the blister is

$$
\delta_{\mathrm{b}}=\frac{3}{4} \frac{\left(1-v^{2}\right) P R_{\mathrm{B}}^{2}}{\pi E h^{3}}
$$

Substituting Eqs. (29) and (30) into Eqs. (1) and (2) gives

$$
\begin{gathered}
G_{\mathrm{I}}=0.6227 \times \frac{1}{2} \frac{P}{\pi R_{\mathrm{B}}^{2}} \delta_{\mathrm{b}}(1+\lambda)^{2} \\
G_{\mathrm{II}}=0.3773 \times \frac{1}{2} \frac{P}{\pi R_{\mathrm{B}}^{2}} \delta_{\mathrm{b}}
\end{gathered}
$$

where

$$
\lambda=\frac{P_{\mathrm{Bb}} h}{1.0063 M_{\mathrm{Bb}}}=\frac{2 h}{1.0063 R_{\mathrm{B}}}
$$

Note that Eqs. (31) and (32) can be directly obtained from Eqs. (5) and (6) by replacing pressure load $p$ with $P /\left(\pi R_{\mathrm{B}}^{2}\right)$. The mode mixity $\rho$ has the same expression as Eq. (11), but with parameter $\lambda$ given by Eq. (33). Its variation with respect to $R_{B} / h$ is also shown in Fig. 2a. Again, it is seen that the through-thickness shear effect is to decrease the mode mixity and reduce the adhesion toughness. It is also mode I dominant. 


\subsection{Membrane stretching mechanical model for large deflection}

The mechanical model in the point load case is very similar to the model developed above for pressure load. Some essential formulae are recorded here. The parameter $\varphi(v)$ becomes

$$
\varphi(v)=0.382 v^{3}+0.013 v^{2}+0.248 v+0.422
$$

The function $f(v)$ now becomes

$$
f(v)=1 /[2 \varphi(v)]+2 \varphi^{2}(v)\left(1-v^{2}\right)
$$

The pressure load $p$ can now be replaced everywhere with $P /\left(\pi R_{\mathrm{B}}^{2}\right)$. The mode I and II ERRs can be obtained [26] as

$$
\begin{aligned}
G_{\mathrm{I}} & =0.6227 \times \frac{P \delta}{8 \pi R_{\mathrm{B}}^{2}} \frac{\left[1-1.557 \sqrt{\left(1-v^{2}\right) \varphi(v)^{3}}\right]^{2}}{\varphi(v) f(v)} \\
G_{\mathrm{II}} & =0.3773 \times \frac{P \delta}{8 \pi R_{\mathrm{B}}^{2}} \frac{\left[1+2.569 \sqrt{\left(1-v^{2}\right) \varphi(v)^{3}}\right]^{2}}{\varphi(v) f(v)}
\end{aligned}
$$

The mode mixity is then

$$
\rho=0.6059\left[\frac{1+2.569 \sqrt{\left(1-v^{2}\right) \varphi(v)^{3}}}{1-1.557 \sqrt{\left(1-v^{2}\right) \varphi(v)^{3}}}\right]^{2}
$$

The mode mixity varies from 5.3568 for $v=0$ to 17.4090 for $v=0.5$. Again, it is constant and mode II dominant. It is also shown in Fig. 2b as the light shaded area. Similarly, $G_{\text {Ic }}$ and $G_{\text {IIc }}$ can be determined by using Eqs. (27) and (28).

\section{Experimental validation}

In this section, the mechanical models developed above are assessed using the experimental results in Ref. [27]. Two groups of experimental results are reported in Ref. [27]. In both groups, the substrate was copper with a thickness of $80 \mu \mathrm{m}$. Each film was transferred to the copper substrate and suspended over a $3 \mathrm{~mm}$-diameter hole. Pressurisation was achieved by pumping deionised water through the hole, resulting in a pressure-blister deflection response and blister growth. The blister deflection and blister radius were measured simultaneously using two microscopes with synchronised cameras, positioned horizontally and vertically respectively. 
In the first group, photoresist films are tested under a pressure load at three different thicknesses, namely $h=10 \mu \mathrm{m}, 31 \mu \mathrm{m}$ and $60 \mu \mathrm{m}$. The photoresist films have a Young's modulus of $E=3.6 \mathrm{GPa}$ and a Poisson's ration of $v=0.35$. Although the thickness of the substrate is not much larger than the thickness of the film, the Young's modulus of copper is in the region of $128 \mathrm{GPa}$ which is much larger than that of the photoresist films. Therefore, the present thin film models are still applicable. Predictions of adhesion toughness, based on the analytical models for various film thicknesses, are summarised in Table 1, in which the predicted value for adhesion toughness (based on the calculated mode I and II adhesion toughness values) for thickness $h=31 \mu \mathrm{m}$ is shown in brackets.

Table 1. Analytical predictions of the adhesion toughness for various photoresist film thicknesses on a copper substrate.

\begin{tabular}{ccccc}
\hline $\begin{array}{c}\text { Thickness } \\
(\mu \mathrm{m})\end{array}$ & Mode mixity & $\begin{array}{c}\text { Measured adhesion } \\
\text { toughness }\left(\mathrm{J} \mathrm{m}^{-2}\right)\end{array}$ & $\begin{array}{c}\text { Mode I toughness } \\
\left(\mathrm{J} \mathrm{m}^{-2}\right)\end{array}$ & $\begin{array}{c}\text { Mode II toughness } \\
\left(\mathrm{J} \mathrm{m}^{-2}\right)\end{array}$ \\
\hline 10 & 2.6583 Eq. (26) & 0.3487 Eq. (24) & & 0.4152 Eq. (28) \\
31 & 0.5189 Eq. (11) & $\begin{array}{c}0.2827 \text { Eq. (8) } \\
(0.2845 \text { Eq. 13) }\end{array}$ & 0.2446 Eq. (27) & \\
60 & 0.4535 Eq. (11) & 0.2805 Eq. (8) & & \\
\hline
\end{tabular}

The experimental results reported in Ref. [27] show that the films with the thickness of $h=10 \mu \mathrm{m}$ behave in the manner of membrane stretching. The measured adhesion toughness $G_{\mathrm{cm}}$ based on Eq. (24) is $G_{\mathrm{cm}}=0.3487 \mathrm{~J} \mathrm{~m}^{-2}$. Note that this value is 1.1285 times greater than the value reported in Ref. [27] because of the difference between Cao et al.'s formula to calculate $G$ and Eq. (24). The mode mixity $\rho_{\mathrm{m}}$ from Eq. (26) is $\rho_{\mathrm{m}}=2.6583$. The experimental results also show that the films with the thicknesses of $h=31 \mu \mathrm{m}$ and $60 \mu \mathrm{m}$ behave in the manner of linear bending. From Eq. (8), the steady-state adhesion toughness $G_{\mathrm{cb}}$ at blister radius $R_{\mathrm{B}}=1530 \mu \mathrm{m}$ are $G_{\mathrm{cb}}=0.2827 \mathrm{~J} \mathrm{~m}^{-2}$ and $0.2805 \mathrm{~J} \mathrm{~m}^{-2}$ respectively. Note that the values reported in Ref. [27] for the films with the thicknesses of $h=31 \mu \mathrm{m}$ and $60 \mu \mathrm{m}$ correspond to $G_{\mathrm{J}}$ in this work. The respective mode mixities $\rho_{\mathrm{b}}$ from Eq. (11) are $\rho_{\mathrm{b}}=0.5189$ and 0.4535 . Now substituting the results, $G_{\mathrm{cm}}=0.3487 \mathrm{~J} \mathrm{~m}^{-2}, \rho_{\mathrm{m}}=2.6583$ for the membrane film of thickness $h=10 \mu \mathrm{m}$, and $G_{\mathrm{cb}}=0.2805 \mathrm{~J} \mathrm{~m}^{-2}, \rho_{\mathrm{b}}=0.4535$ for the linear bending film of thickness $h=60 \mu \mathrm{m}$ into Eqs. (27) and (28), the mode I and II adhesion toughness are determined to be $G_{\text {Ic }}=0.2446 \mathrm{~J} \mathrm{~m}^{-2}$ and $G_{\text {IIc }}=0.4152 \mathrm{~J} \mathrm{~m}^{-2}$. To examine the accuracy of these values, the adhesion toughness of the film with the thickness 
of $h=31 \mu \mathrm{m}$ is now calculated analytically using Eq. (13). Substituting $G_{\text {Ic }}=0.2446 \mathrm{~J} \mathrm{~m}^{-2}$, $G_{\text {IIc }}=0.4152 \mathrm{~J} \mathrm{~m}^{-2}$ and $\rho=\rho_{\mathrm{b}}=0.5189$ for the film with thickness of $h=31 \mu \mathrm{m}$ into Eq. (13) gives $G_{\mathrm{c}}=0.2845 \mathrm{~J} \mathrm{~m}^{-2}$, which is in excellent agreement with the test result of $G_{\mathrm{cb}}=0.2827 \mathrm{~J} \mathrm{~m}^{-2}$.

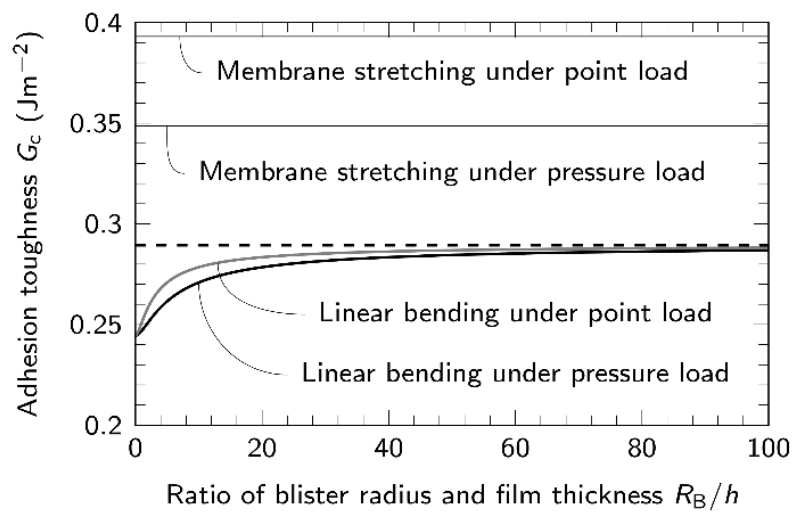

Fig. 4. Variation of adhesion toughness $G_{\mathrm{c}}$ at the photoresist/copper interface with respect to $R_{\mathrm{B}} / h$ under the four test conditions.

Figure 4 shows the variation of the adhesion toughness $G_{\mathrm{c}}$ with respect to $R_{\mathrm{B}} / \mathrm{h}$ under the four test conditions, namely, linear bending and membrane stretching under pressure and point loading conditions. The adhesion toughness $G_{\text {с }}$ approaches $G_{\text {Iс }}$ for small $R_{\mathrm{B}} / h$ and approaches $G_{\mathrm{c}}=1.6059 G_{\mathrm{IC}} G_{\text {IIc }} /\left(0.6059 G_{\text {Ic }}+G_{\text {IIc }}\right)$ for large $R_{\mathrm{B}} / h$ for linear bending with both pressure and point loading, as seen from Eqs. (11) and (13). It is interesting to note that thicker films have smaller adhesion toughness. Also, note that the two curves under linear bending conditions appear similar to the usual fracture resistance curve, but they have different meanings: Here, the variation of adhesion toughness is due to the changing mode mixity with the mode I and II adhesion toughness $G_{\text {Ic }}$ and $G_{\text {IIc }}$ remaining constant. In the fracture resistance curve, however, the variation is due to nonlinear behaviour like ductile fracture, in which there is a plastic zone at the crack tip which increases in size with crack extension; or in fibre-reinforced materials it can be caused by fibre-bridging. The fracture resistance curve results from the increasing mode I and II adhesion toughness $G_{\text {Ic }}$ and $G_{\text {IIc }}$ with crack extension rather than from the changing mode mixity. 
In contrast, for membrane stretching conditions, the adhesion toughness $G_{\mathrm{c}}$ remains constant with respect to $R_{\mathrm{B}} / h$ under both pressure and point loading conditions due to the constant mode mixity, as shown in Eqs. (26) and (38) respectively. Since mode II is dominant, $G_{\mathrm{c}}$ is always larger than for linear bending test conditions, for which mode I is dominant.

In the second group of test results, monolayer graphene is sandwiched by the same copper substrate and the photoresist film as used in the first group of tests. The thickness of the monolayer graphene is about $0.347 \mathrm{~nm}$ [26]. Even taking into account the large Young's modulus of graphene at about $1000 \mathrm{GPa}$, its effective thickness is still much smaller than the thickness of the photoresist films and it is therefore ignored in the present work. The addition of the graphene layer, however, changes the adhesion toughness of the photoresist film. Predictions of adhesion toughness, based on the analytical models for various film thicknesses, are summarised in Table 2, in which the predicted value for adhesion toughness (based on the calculated mode I and II adhesion toughness values) for thickness $h=31 \mu \mathrm{m}$ is shown in brackets.

Table 2. Analytical predictions of the adhesion toughness for various thicknesses of a monolayer graphene/photoresist sandwich film on a copper substrate.

\begin{tabular}{|c|c|c|c|c|}
\hline $\begin{array}{l}\text { Thickness } \\
\qquad(\mu \mathrm{m})\end{array}$ & Mode mixity & $\begin{array}{l}\text { Measured adhesion } \\
\text { toughness } \\
\left(\mathrm{J} \mathrm{m}^{-2}\right)\end{array}$ & $\begin{array}{l}\text { Mode I toughness } \\
\qquad\left(\mathrm{J} \mathrm{m}^{-2}\right)\end{array}$ & $\begin{array}{l}\text { Mode II toughness } \\
\qquad\left(\mathrm{J} \mathrm{m}^{-2}\right)\end{array}$ \\
\hline 10 & 2.6583 Eq. (26) & 0.4435 Eq. (24) & \multirow{3}{*}{0.3240 Eq. (27) } & \multirow{3}{*}{0.5149 Eq. (28) } \\
\hline 31 & 0.5189 Eq. (11) & $\begin{array}{c}0.3711 \text { Eq. (8) } \\
\text { (0.3710 Eq. 13) }\end{array}$ & & \\
\hline 60 & 0.4535 Eq. (11) & 0.3664 Eq. (8) & & \\
\hline
\end{tabular}

Again, the experimental results reported in Ref. [27] show that the films with the thickness of $h=10 \mu \mathrm{m}$ behave in the manner of membrane stretching. The measured adhesion toughness $G_{\mathrm{cm}}$ based on Eq. (24) is $G_{\mathrm{cm}}=0.4435 \mathrm{~J} \mathrm{~m}^{-2}$. Note that this value is 1.1285 times greater than the value reported in Ref. [27] because of the difference between Cao et al.'s formula to calculate $G$ and Eq. (24). The mode mixity $\rho_{\mathrm{m}}$ from Eq. (26) is $\rho_{\mathrm{m}}=2.6583$. Also, the experimental results show that the films with thicknesses of $h=31 \mu \mathrm{m}$ and $60 \mu \mathrm{m}$ behave in the manner of linear bending. From Eq. (8), the steady-state adhesion toughness $G_{\mathrm{cb}}$ at blister radius $R_{\mathrm{B}}=1530 \mu \mathrm{m}$ are $G_{\mathrm{cb}}=0.3711 \mathrm{~J} \mathrm{~m}^{-2}$ and $0.3664 \mathrm{~J} \mathrm{~m}^{-2}$ respectively. Note that the values reported in Ref. [27] for the films with the thicknesses of $h=31 \mu \mathrm{m}$ and 
$60 \mu \mathrm{m}$ correspond to $G_{\mathrm{J}}$ in this work. The respective mode mixities $\rho_{\mathrm{b}}$ from Eq. (11) are $\rho_{\mathrm{b}}=0.5189$ and 0.4535 . Now, substituting the results, $G_{\mathrm{cm}}=0.4435 \mathrm{~J} \mathrm{~m}^{-2}, \rho_{\mathrm{m}}=2.6583$ for the membrane film of thickness $h=10 \mu \mathrm{m}$, and $G_{\mathrm{cb}}=0.3664 \mathrm{~J} \mathrm{~m}^{-2}, \rho_{\mathrm{b}}=0.4535$ for the linear bending film of thickness $h=60 \mu \mathrm{m}$ into Eqs. (27) and (28), mode I and II adhesion toughness are determined to be $G_{\text {Ic }}=0.3240 \mathrm{~J} \mathrm{~m}^{-2}$ and $G_{\text {IIc }}=0.5149 \mathrm{~J} \mathrm{~m}^{-2}$, which are significantly larger than the corresponding $G_{\text {Ic }}=0.2446 \mathrm{~J} \mathrm{~m}^{-2}$ and $G_{\text {IIc }}=0.4152 \mathrm{~J} \mathrm{~m}^{-2}$ from the first group of tests. Similarly, to examine the accuracy of these values, the adhesion toughness of the film with the thickness of $h=31 \mu \mathrm{m}$ is now calculated analytically using Eq. (13). Substituting $G_{\text {Ic }}=0.3240 \mathrm{~J} \mathrm{~m}^{-2}, G_{\text {IIc }}=0.5149 \mathrm{~J} \mathrm{~m}^{-2}$ and $\rho=\rho_{\mathrm{b}}=0.5189$ for the film with thickness of $h=31 \mu \mathrm{m}$ into Eq. (13) gives $G_{\mathrm{c}}=0.3710 \mathrm{~J} \mathrm{~m}^{-2}$, which again is in excellent agreement with test result of $G_{\mathrm{cb}}=0.3711 \mathrm{~J} \mathrm{~m}^{-2}$.

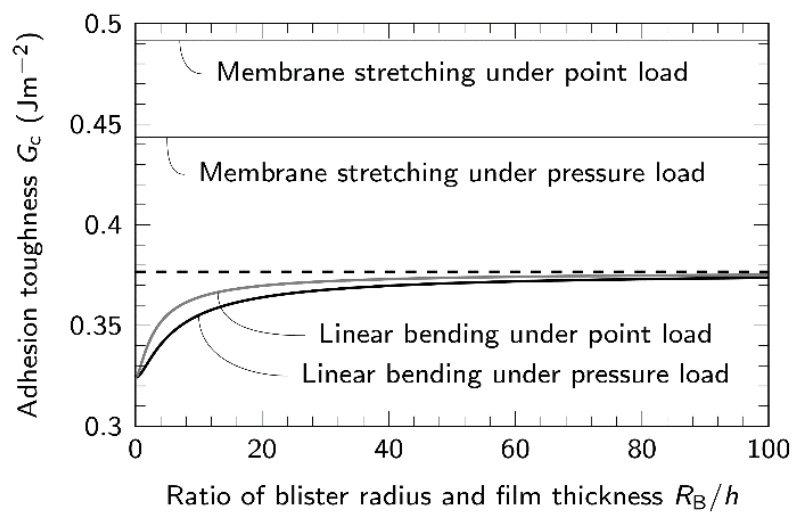

Fig. 5. Variation of adhesion toughness $G_{c}$ at the graphene/copper interface with respect to $R_{\mathrm{B}} / h$ under the four test conditions.

Figure 5 shows the variation of the adhesion toughness $G_{\mathrm{c}}$ at the graphene/copper interface with respect to $R_{\mathrm{B}} / h$ under the four test conditions. Similar facts are observed to those from Fig. 4 (which shows $G_{\mathrm{c}}$ for the photoresist/copper interface), but with a distinct difference: The adhesion toughness $G_{c}$ in all the four test conditions are now significantly larger than the corresponding ones for the photoresist/copper interfaces. The mono graphene layer increases the adhesion toughness.

Due to the lack of experimental results for the case of point loads, it is not possible to assess the developed mechanical model for the point load case. In the case of multilayer 
graphene membranes, however, the latest work [26] reports comparisons between the model and experimental results and excellent agreement is observed.

\section{Conclusions}

For linear bending with small deflection, the interface fracture of thin film blisters is mode I dominant. The through-thickness shear force makes an extra contribution to the mode I ERR and decreases the mode mixity. The thicker the film is, the smaller the adhesion toughness is. For membrane stretching with large deflection, the interface fracture of thin film blisters is mode II dominant. Membrane films consequently have larger adhesion toughness. Furthermore, the through-thickness shear force has no effect on the mode mixity which is only dependent on the Poisson's ratio. The large mode mixity difference between these two limiting cases enables the mode I and II adhesion toughness of thin films to be accurately determined. Experimental results show that the method has a good capability.

\section{References}

[1] L.B. Freund, S. Suresh, Thin Film Materials: Stress, Defect Formation and Surface Evolution, Cambridge University Press, 2004.

[2] M.R. Begley, J.W. Hutchinson, The Mechanics and Reliability of Films, Multilayers and Coatings, Cambridge University Press, 2017.

[3] H. Chai, Three-dimensional fracture analysis of thin-film debonding, Int. J. Fract. 46 (1990) 237-256. doi:10.1007/BF00037155.

[4] J.W. Hutchinson, M.D. Thouless, E.G. Liniger, Growth and configurational stability of circular, buckling-driven film delaminations, Acta Metall. Mater. 40 (1992) 295-308. doi:10.1016/0956-7151(92)90304-W.

[5] H.M. Jensen, I. Sheinman, Straight-sided, buckling-driven delamination of thin films at high stress levels, Int. J. Fract. 110 (2001) 371-385. doi:10.1023/A:1010821918325.

[6] M.W. Moon, H.M. Jensen, J.W. Hutchinson, K.H. Oh, A.G. Evans, The characterization of telephone cord buckling of compressed thin films on substrates, J. Mech. Phys. Solids. 50 (2002) 2355-2377. doi:10.1016/S0022-5096(02)00034-0.

[7] H.M. Jensen, I. Sheinman, Numerical analysis of buckling-driven delamination, Int. J. Solids Struct. 39 (2002) 3373-3386. doi:10.1016/S0020-7683(02)00158-0.

[8] J.W. Hutchinson, M.Y. He, A.G. Evans, The influence of imperfections on the 
nucleation and propagation of buckling driven delaminations, J. Mech. Phys. Solids. 48 (2000) 709-734. doi:10.1016/S0022-5096(99)00050-2.

[9] M.Y. He, A.G. Evans, J.W. Hutchinson, Effects of morphology on the decohesion of compressed thin films, Mater. Sci. Eng. A. 245 (1998) 168-181. doi:10.1016/S09215093(97)00848-4.

[10] S. Wang, C.M. Harvey, B. Wang, Room temperature spallation of $\alpha$-alumina films grown by oxidation, Eng. Fract. Mech. 178 (2017) 401-415. doi:10.1016/j.engfracmech.2017.03.002.

[11] C.M. Harvey, B. Wang, S. Wang, Spallation of thin films driven by pockets of energy concentration, Theor. Appl. Fract. Mech. $92 \quad$ (2017) 1-12. doi:10.1016/j.tafmec.2017.04.011.

[12] B. Yuan, C.M. Harvey, R.C. Thomson, G.W. Critchlow, S. Wang, Telephone cord blisters of thin films driven by pockets of energy concentration, In review.

[13] B. Yuan, C.M. Harvey, R.C. Thomson, G.W. Critchlow, S. Wang, A new spallation mechanism of thermal barrier coatings on aero-engine turbine blades, In review.

[14] V.K. Tolpygo, D.R. Clarke, Spalling failure of $\alpha$-alumina films grown by oxidation: I. Dependence on cooling rate and metal thickness, Mater. Sci. Eng. A. 278 (2000) 142150. doi:10.1016/S0921-5093(99)00581-X.

[15] V.K. Tolpygo, D.R. Clarke, Spalling failure of $\alpha$-alumina films grown by oxidation. II. Decohesion nucleation and growth, Mater. Sci. Eng. A. 278 (2000) 151-161. doi:10.1016/S0921-5093(99)00582-1.

[16] J.W. Obreimoff, The Splitting Strength of Mica, Proc. R. Soc. A Math. Phys. Eng. Sci. 127 (1930) 290-297. doi:10.1098/rspa.1930.0058.

[17] K. Kendall, Thin-Film Peeling - The Elastic Term, J. Phys. D. Appl. Phys. 8 (1975) 1449-1452. doi:10.1088/0022-3727/8/13/005.

[18] A.G. Evans, E.A. Charles, Fracture Toughness Determinations by Indentation, J. Am. Ceram. Soc. 59 (1976) 371-372. doi:10.1111/j.1151-2916.1976.tb10991.x.

[19] A.T. Akono, F.J. Ulm, An improved technique for characterizing the fracture toughness via scratch test experiments, Wear. 313 (2014) 117-124. doi:10.1016/j.wear.2014.02.015.

[20] H. Dannenberg, Measurement of adhesion by a blister method, J. Appl. Polym. Sci. 5 (1961) 125-134. doi:10.1002/app.1961.070051401. 
[21] H.M. Jensen, The blister test for interface toughness measurement, Eng. Fract. Mech. 40 (1991) 475-486. doi:10.1016/0013-7944(91)90144-P.

[22] H.M. Jensen, Analysis of mode mixity in blister tests, Int. J. Fract. 94 (1998) 79-88. doi:10.1023/A:1007555313162.

[23] A. Sofla, E. Seker, J.P. Landers, M.R. Begley, PDMS-Glass Interface Adhesion Energy Determined Via Comprehensive Solutions for Thin Film Bulge/Blister Tests, J. Appl. Mech. 77 (2010) 31007. doi:10.1115/1.4000428.

[24] B.M. Malyshev, R.L. Salganik, The strength of adhesive joints using the theory of cracks, Int. J. Fract. Mech. 1 (1965) 114-128. doi:10.1007/BF00186749.

[25] Y. Wang, L. Tong, Closed-form Formulas for Adhesion Energy of Blister Tests Under Pressure and Point Load, J. Adhes. 92 (2016) 171-193. doi:10.1080/00218464.2015.1008630.

[26] J.D. Wood, C.M. Harvey, S. Wang, Adhesion toughness of multilayer graphene films, Nat. Commun. 8 (2017) 1952. doi:10.1038/s41467-017-02115-w.

[27] Z. Cao, L. Tao, D. Akinwande, R. Huang, K.M. Liechti, Mixed-mode tractionseparation relations between graphene and copper by blister tests, Int. J. Solids Struct. 84 (2016) 147-159. doi:10.1016/j.ijsolstr.2016.01.023.

[28] S.P. Koenig, N.G. Boddeti, M.L. Dunn, J.S. Bunch, Ultrastrong adhesion of graphene membranes, Nat. Nanotechnol. 6 (2011) 543-546. doi:10.1038/nnano.2011.123.

[29] Z. Zong, C.-L. Chen, M.R. Dokmeci, K. Wan, Direct measurement of graphene adhesion on silicon surface by intercalation of nanoparticles, J. Appl. Phys. 107 (2010) 26104. doi:10.1063/1.3294960.

[30] J.D. Wood, C.M. Harvey, S. Wang, Partition of mixed-mode fractures in 2D elastic orthotropic laminated beams under general loading, Compos. Struct. 149 (2016) 239_ 246. doi:10.1016/j.compstruct.2016.04.016.

[31] C.M. Harvey, J.D. Wood, S. Wang, A. Watson, A novel method for the partition of mixed-mode fractures in 2D elastic laminated unidirectional composite beams, Compos. Struct. 116 (2014) 589-594. doi:10.1016/j.compstruct.2014.05.041.

[32] J.W. Hutchinson, Z. Suo, Mixed Mode Cracking in Layered Materials, in: Adv. Appl. Mech., 1991: pp. 63-191. doi:10.1016/S0065-2156(08)70164-9.

[33] C.M. Harvey, S. Wang, Experimental assessment of mixed-mode partition theories, Compos. Struct. 94 (2012) 2057-2067. doi:10.1016/j.compstruct.2012.02.007. 
[34] C.M. Harvey, M.R. Eplett, S. Wang, Experimental assessment of mixed-mode partition theories for generally laminated composite beams, Compos. Struct. 124 (2015) 10-18. doi:10.1016/j.compstruct.2014.12.064. 